\title{
Radiation Therapy for Extremity Soft Tissue Sarcoma: In the Absence of a Clear Survival Benefit, Why Do We Give It?
}

\author{
Elizabeth H. Baldini, MD, MPH ${ }^{1,4}$ and Chandrajit Raut, $\mathrm{MD}^{2,3}$ \\ ${ }^{1}$ Radiation Oncology, Brigham and Women's Hospital, Dana-Farber Cancer Institute, Boston, MA; ${ }^{2}$ Surgery, Brigham and \\ Women's Hospital, Boston, MA; ${ }^{3}$ Surgery, Harvard Medical School, Boston, MA; ${ }^{4}$ Radiation Oncology, Harvard Medical \\ School, Boston, MA
}

Due in large part to several sentinel contributions from the National Cancer Institute (NCI), the local management of extremity soft tissue sarcoma (ESTS) today typically results in excellent local control and very good limb function. In 1982, Rosenberg et al. ${ }^{1}$ showed equivalent 5-year survival rates for limb-sparing surgery (LSS) plus radiation therapy (RT) compared with amputation and an acceptable $15 \%$ local recurrence (LR) rate for LSS plus RT. Following publication of this landmark trial, amputation rates appropriately plummeted. In 1998, Yang et al. ${ }^{2}$ reported results from a second NCI randomized trial that compared LSS plus RT with LSS alone and showed a clear significant local control benefit for RT for both high- and low-grade ESTS. A randomized trial from Memorial Sloan-Kettering Cancer Center (MSKCC) in 1996 affirmed the local control advantage for RT (in the form of brachytherapy) in addition to LSS. $^{3}$ Several nonrandomized series have reported LR rates $<15 \%$ for LSS alone without RT, but others have shown unacceptably high rates of LR with this approach. ${ }^{4-8}$ Given the conflicting results for surgery alone from nonrandomized reports, and the clear local control advantage with RT demonstrated by randomized trials, the standard of care for most high-grade ESTS is LSS plus RT.

The main and undisputed benefit of adjuvant RT is improved local control, and local control rates for LSS plus RT are $<15 \%$ in modern series. ${ }^{9-12}$ However, the effect of $\mathrm{RT}$ on overall survival is ambiguous. The aforementioned

(C) Society of Surgical Oncology 2014

First Received: 5 April 2014;

Published Online: 17 May 2014

E. H. Baldini, MD, MPH

e-mail: ebaldini@partners.org randomized trials as well as the 20-year update of the NCI trial reported by Beane et al. that accompanies this editorial, fail to show a statistically significant difference in survival with the addition of RT. ${ }^{1-3,13}$

Since RT has its own treatment-related toxicities and is not associated with an improvement in overall survival, should we stop using RT in conjunction with LSS? The report by Beane et al. shows a trend toward higher 20-year survival rates for LSS plus RT compared with LSS alone (71 vs. $64 \%, p=0.22$ ). As the authors point out, this study was only powered to detect a $21 \%$ survival difference. On the other hand, a review of 6,960 patients with high-grade ESTS showed a statistically significant improved 3-year survival rate of $73 \%$ for LSS plus RT compared with $63 \%$ for LSS alone $(p<0.001) .{ }^{14}$ It is quite possible that adjuvant RT for ESTS does in fact confer a statistically significant survival advantage, but due to small patient numbers in most series, such a benefit has not been reliably demonstrated. This was the case for breast cancer. Most individual trials failed to show a significant association between local control and survival. ${ }^{15,16}$ Nevertheless, patients with breast cancer were still treated with RT because of the local control advantage it conferred. Ultimately, a meta-analysis of 42,000 patients demonstrated a clear link between improved local control and superior survival. ${ }^{17}$

Another potential benefit of adjuvant RT relates to the consequences of a LR. The development of a LR necessitates further surgery or surgeries and possible RT, and it may result in greater long-term toxicity than if RT had been delivered after the first definitive resection. In addition, development of a LR can have a devastating psychological impact.

On the other hand, delivery of adjuvant RT is associated with toxicities, the severity of which must be factored into 
the decision of whether to recommend such treatment. The Beane report assessed toxicity rates via telephone survey for 54 of the initial 141 patients (38\%) enrolled in the NCI LSS plus RT versus LSS alone trial. ${ }^{13}$ There were no statistically significant differences between groups, but the toxicity rates trended higher for the LSS plus RT group compared with the LSS alone group: clinically significant edema (25 vs. $12 \%$ ), functional limb deficits (15 vs. $12 \%$ ), bone fracture (10 vs. $4 \%$ ), wound complications (17 vs. $12.5 \%$, respectively for all comparisons.) These patientreported outcomes are an important contribution to the literature, but it is important to interpret them in the context of the treatment era. These patients were treated prior to 1991 with 2D technology rather than 3D-based treatment planning. Patients with high-grade tumors were also treated with concurrent chemotherapy. These factors are likely associated with higher long-term toxicity rates compared with modern era treatment that largely uses 3D and intensity-modulated RT (IMRT) and rarely uses concurrent chemotherapy. Three recent groups using primarily IMRT reported Grade 2 or greater toxicity rates for LSS plus RT. These toxicity rates are likely more representative of current practice: edema (5-11\%), joint stiffness (5.5-14.5\%), and subcutaneous fibrosis (5.5-9\%) (Alektiar, personal communication). ${ }^{18,19}$ With respect to fracture rates, Dickie et al. ${ }^{20}$ defined RT dose metrics which, when achieved, keep fracture rates $<2 \%$. Lastly, O'Sullivan et al. ${ }^{18}$ demonstrated that if the surgical flap can be spared high dose during preoperative $\mathrm{RT}$, wound complication rates are $<15 \%$.

In conclusion, the addition of RT to LSS for ESTS clearly improves local control. It is quite possible the improved local control afforded by RT is also associated with improved overall survival, but such an effect has not been clearly demonstrated. RT-related long-term toxicities occur. With modern treatment planning, use of IMRT, and current improved understanding of normal tissue dose tolerances, rates of clinically significant toxicities such as edema, fibrosis, joint stiffness, and fracture are quite low. However, we as sarcoma oncologists should be judicious with our recommendations for RT. In particular, we should avoid RT in patients with little risk of LR such as those with tumors that are low grade, superficial, and indolent (e.g., atypical lipomatous tumors).

In our opinion, for most patients with high-grade ESTS, the relative benefits of modern-era RT outweigh the relative toxicities, and we continue to recommend the approach of LSS plus RT. Having said that, we must always strive to do better. We support further investigations to reduce RTrelated toxicity such as the ongoing assessments of smaller radiation treatment fields, ${ }^{21,22}$ selective RT dose reduction, and efforts to further understand normal organ dose tolerances. We acknowledge there is likely a subset of patients who can be spared RT altogether, and a prospective trial to elucidate this group would be very worthwhile.

\section{REFERENCES}

1. Rosenberg SA, Tepper J, Glatstein E, Costa J, Baker A, Brennan $\mathrm{M}$, et al. The treatment of soft-tissue sarcomas of the extremities: prospective randomized evaluations of (1) limb-sparing surgery plus radiation therapy compared with amputation and (2) the role of adjuvant chemotherapy. Ann Surg. 1982;196:305-15.

2. Yang JC, Chang AE, Baker AR, Sindelar WF, Danforth DN, Topalian SL, et al. Randomized prospective study of the benefit of adjuvant radiation therapy in the treatment of soft tissue sarcomas of the extremity. J Clin Oncol. 1998;16:197-203.

3. Pisters PW, Harrison LB, Leung DH, Woodruff JM, Casper ES, Brennan MF. Long-term results of a prospective randomized trial of adjuvant brachytherapy in soft tissue sarcoma. J Clin Oncol. 1996;14:859-68.

4. Pisters PW, Pollock RE, Lewis VO, Yasko AW, Cormier JN, Respondek PM, et al. Long-term results of prospective trial of surgery alone with selective use of radiation for patients with T1 extremity and trunk soft tissue sarcomas. Ann Surg. 2007;246:675-81; discussion 681-2.

5. Baldini EH, Goldberg J, Jenner C, Manola JB, Demetri GD, Fletcher $\mathrm{CD}$, et al. Long-term outcomes after function-sparing surgery without radiotherapy for soft tissue sarcoma of the extremities and trunk. J Clin Oncol. 1999; 17:3252-9.

6. Rydholm A, Gustafson P, Rooser B, Willen H, Akerman M, Herrlin $\mathrm{K}$, et al. Limb-sparing surgery without radiotherapy based on anatomic location of soft tissue sarcoma. J Clin Oncol. 1991;9:1757-65.

7. Khanfir K, Alzieu L, Terrier P, Le Pechoux C, Bonvalot S, Vanel $\mathrm{D}$, et al. Does adjuvant radiation therapy increase loco-regional control after optimal resection of soft-tissue sarcoma of the extremities? Eur J Cancer. 2003;39:1872-80.

8. Cahlon O, Spierer M, Brennan MF, Singer S, Alektiar KM. Longterm outcomes in extremity soft tissue sarcoma after a pathologically negative re-resection and without radiotherapy. Cancer. 2008;112:2774-9.

9. O'Sullivan B, Davis A, Turcotte R, Bell R, Wunder J, Catton C, et al. Five-year results of a randomized phase III trial of preoperative vs post-operative radiotherapy in extremity soft tissue sarcoma. J Clin Oncol. 2004 ASCO Annual Meeting Proceedings 2004; 22:Abstract 9007.

10. Gronchi A, Casali PG, Mariani L, Miceli R, Fiore M, Lo Vullo S, et al. Status of surgical margins and prognosis in adult soft tissue sarcomas of the extremities: a series of patients treated at a single institution. J Clin Oncol. 2005;23:96-104.

11. Baldini E, Lapidus M, Wang Q, Manola J, Orgill DP, Pomahac B, et al. Predictors for major wound complications following preoperative radiotherapy and surgery for soft-tissue sarcoma of the extremities and trunk: importance of tumor proximity to skin surface. Ann Surg Oncol. 2013;20:1494-9.

12. Folkert MR, Singer S, Brennan MF, Folkert WK, Crago AM, Alektiar KM. Local control comparison of conventional and intensity modulated radiation therapy (IMRT) for primary softtissue sarcomas of the extremity. Int J Radiat Oncol Biol Phys. 2013;87:S63.

13. Beane JD, Yang JC, White D, Steinberg SM, Rosenberg SA, Rudloff U. Efficacy of adjuvant radiation therapy in the treatment of soft tissue sarcoma of the extremity: 20-year follow up of a randomized prospective trial. Ann Surg Oncol. 2014. doi:10. 1245/s10434-014-3732-4. 
14. Koshy M, Rich SE, Mohiuddin MM. Improved survival with radiation therapy in high-grade soft tissue sarcomas of the extremities: a SEER analysis. Int J Radiat Oncol Biol Phys. 2010;77:203-9.

15. Fisher B, Jeong J-H, Anderson S, Bryant J, Fisher ER, Wolmark $\mathrm{N}$. Twenty-five-year follow-up of a randomized trial comparing radical mastectomy, total mastectomy, and total mastectomy followed by irradiation. $N$ Engl J Med. 2002;347:567-75.

16. Fisher B, Anderson S, Bryant J, Margolese RG, Deutsch M, Fisher ER, et al. Twenty-year follow-up of a randomized trial comparing total mastectomy, lumpectomy, and lumpectomy plus irradiation for the treatment of invasive breast cancer. $N$ Engl $J$ Med. 2002;347:1233-41.

17. Clarke M, Collins R, Darby S, Davies C, Elphinstone P, Evans E, et al. Effects of radiotherapy and of differences in the extent of surgery for early breast cancer on local recurrence and 15-year survival: an overview of the randomised trials. Lancet. 2005;366:2087-106.

18. O'Sullivan B, Griffin AM, Dickie CI, Sharpe MB, Chung PW, Catton $\mathrm{CN}$, et al. Phase 2 study of preoperative image-guided intensity-modulated radiation therapy to reduce wound and combined modality morbidities in lower extremity soft tissue sarcoma. Cancer. 2013;119:1878-84.

19. Wang D, Zhang Q, Eisenberg B, Kane J, Li X, Lucas D, et al. Significant reduction of radiation related morbidities in the extremity sarcoma patients treated with image guided radiation therapy to reduced target volume: results of RTOG 0630. Int J Radiat Oncol Biol Phys. 2013;87:S63.

20. Dickie CI, Parent AL, Griffin AM, Fung S, Chung PW, Catton CN, et al. Bone fractures following external beam radiotherapy and limb-preservation surgery for lower extremity soft tissue sarcoma: relationship to irradiated bone length, volume, tumor location and dose. Int J Radiat Oncol Biol Phys. 2009;75:1119-24.

21. Radiation therapy in treating patients who have undergone surgery for soft tissue sarcoma of the arms, hands, legs, or feet. VORTEX. U.S. National Institutes of Health. http://clinicaltrials. gov/ct2/show/NCT00423618. Accesssed 1 April 2014.

22. Image-guided radiation therapy in treating patients with primary soft tissue sarcoma of the shoulder, arm, hip, or leg. RTOG-0630. U.S. National Institutes of Health. http://www.clinicaltrials.gov/ ct2/show/study/NCT00589121?term=RTOG+0630\&rank=1. Accesssed 1 April 2014. 